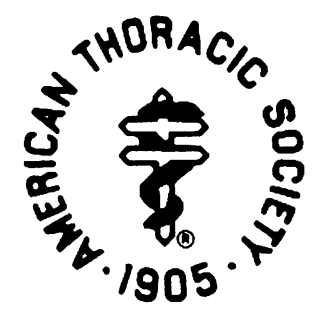

Volume 9

Number 4

October 1993

AMERICAN JOURNAL OF

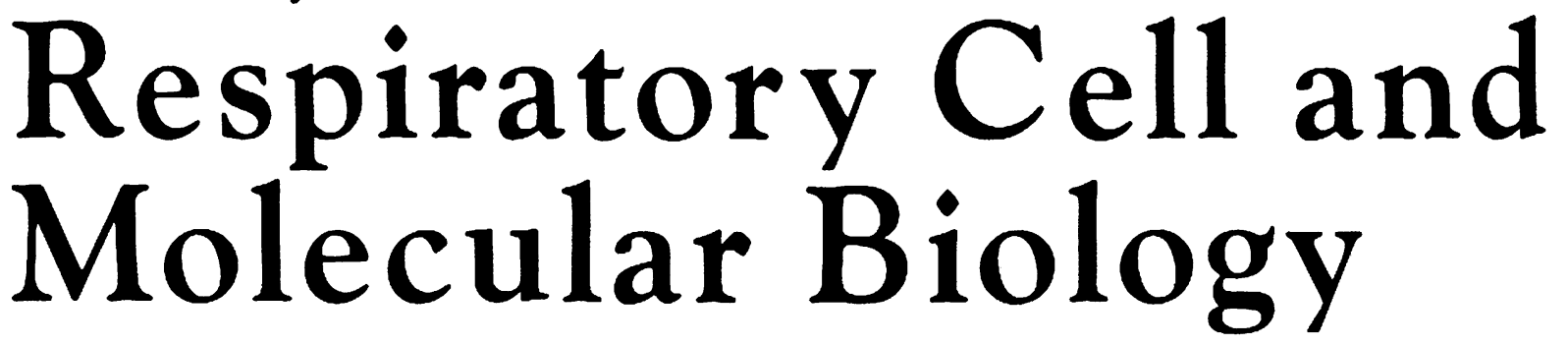

AN OFFICIAL JOURNAL OF THE AMERICAN THORACIC SOCIETY MEDICAL SECTION OF THE AMERICAN LUNG ASSOCIATION 


\section{American Journal of Respiratory Cell and Molecular Biology}

Volume 9, Number 4, October 1993

Contents

Perspective

347 Modulation of the Pulmonary Cytochrome P450 System as a Factor in Pulmonary-selective Toxic Responses: Fact and Fiction. Richard M. Philpot

Rapid Communications

350 Intercellular Adhesion Molecule-1 Expression on the Alveolar Epithelium and Its Modification by Hyperoxia. Bor-Hwang Kang, James D. Crapo, Craig D. Wegner, L. Gordon Letts, and Ling-Yi Chang

356 T Cells Are the Principal Source of Interleukin-5 mRNA in Allergen-induced Rhinitis. Sun Ying, S. R. Durham, J. Barkans, K. Masuyama, M. Jacobson, S. Rak, A. Löwhagen, R. Moqbel, A. B. Kay, and Q. A. Hamid

Articles

361 Parainfluenza (Sendai) Virus Infects Ciliated Cells and Secretory Cells but Not Basal Cells of Rat Tracheal Epithelium. P. P. Massion, C. C. P. Funari, I. Ueki, S. Ikeda, D. M. McDonald, and J. A. Nadel

371 Nitric Oxide Synthase in Human and Rat Lung: Immunocytochemical and Histochemical Localization. L. Kobzik, D. S. Bredt, C. J. Lowenstein, J. Drazen, B. Gaston, D. Sugarbaker, and J. S. Stamler

378 Production of Interleukin-5 and Granulocyte/Macrophage Colony-stimulating Factor by $\mathrm{T}$ Cells of Patients with Bronchial Asthma in Response to Dermatophagoides farinae and Its Relation to Eosinophil Colony-stimulating Factor. Toshihiko Kamei, Toshio Ozaki, Koji Kawaji, Kayo Banno, Takahiro Sano, Masahiko Azuma, and Takeshi Ogura

386 Tumor Necrosis Factor Increases the Elastolytic Potential of Adherent Neutrophils: A Role for Hypochlorous Acid. Zhi-Wu She, Mark D. Wewers, Danuta J. Herzyk, and W. Bruce Davis

393 Increases in Lung Tissue Expression of Intercellular Adhesion Molecule-1 Are Associated with Hyperoxic Lung Injury and Inflammation in Mice. Stephen E. Welty, Julian L. Rivera, Jonathan F. Elliston, Charles V. Smith, Taimur Zeb, Christie M. Ballantyne, Charles A. Montgomery, and Thomas N. Hansen

401 Protein Phosphorylation Responses in Normal and Cystic Fibrosis Airway Epithelial Cell Lines. Jonathan A. Cohn, Jolanta Kole, and James R. Yankaskas

405 Effect of Phospholipase C Inhibitor U-73122 on Antigen-induced Airway Smooth Muscle Contraction in Guinea Pigs. Hassan Salari, Andrew Bramley, John Langlands, Sandra Howard, Moira Chan-Yeung, Henry Chan, and Robert Schellenberg

411 Activation by Histamine of Bronchial Epithelial Cells from Nonasthmatic Subjects. Antonio M. Vignola, Alison M. Campbell, Pascal Chanez, Pascale Lacoste, François B. Michel, Philippe Godard, and Jean Bousquet

418 Temporal Alterations in Specific Basement Membrane Components in Lungs from Monocrotaline-treated Rats. David W. Lipke, Santosh S. Arcot, Mark N. Gillespie, and Jack W. Olson

$429 \mathrm{BQ123}$, an $\mathrm{ET}_{\mathrm{A}}$ Receptor Antagonist, Inhibits Endothelin-1-mediated Proliferation of Human Pulmonary Artery Smooth Muscle Cells. Martin R. Zamora, Edward C. Dempsey, Sandra J. Walchak, and Thomas J. Stelzner

434 A Small Proline-rich Protein Regulated by Vitamin A in Tracheal Epithelial Cells Is Induced in Lung Tumors. Johannes Tesfaigzi, Paul S. Wright, Victor Oreffo, Gang An, Reen Wu, and Don M. Carlson

441 Receptor-mediated Gene Transfer to Airway Epithelial Cells in Primary Culture. C. E. Harris, S. Agarwal, P.-c. Hu, E. Wagner, and D. T. Curiel

448 Inhibition of Human Lung Cancer Cell Line Growth by an Anti-p185 ${ }^{\text {Her2 }}$ Antibody. Jeffrey A. Kern, Lisa Torney, David Weiner, Adi Gazdar, H. Michael Shepard, and Brian Fendly

455 Release of Interleukin-8, Interleukin-6, and Colony-stimulating Factors by Upper Airway Epithelial Cells: Implications for Cystic Fibrosis. Marie Bédard, Carol D. McClure, Neal L. Schiller, Caroline Francoeur, André Cantin, and Michel Denis 


\title{
Receptor-mediated Gene Transfer to Airway Epithelial Cells in Primary Culture
}

\author{
C. E. Harris, S. Agarwal, P.-c. Hu, E. Wagner, and D. T. Curiel
}

Departments of Pediatrics and Medicine, University of North Carolina at Chapel Hill, Chapel Hill, North Carolina; Research Institute of Molecular Pathology, Vienna, Austria; and Department of Pulmonary and Critical Care Medicine, Gene Therapy Program of the UAB Cancer Center, Department of Medicine, University of Alabama at Birmingham, Birmingham, Alabama

\begin{abstract}
A variety of methods have been utilized for gene transfer to the cells of the airway epithelium. These have included DNA-mediated mechanisms of gene transfer as well as recombinant viral vectors. Despite the availability of these methods, limitations in their utility warrant the development of alternate systems. As an alternative, receptor-mediated endocytosis using transferrin-polylysine conjugates has been shown to transduce immortalized airway epithelial cells efficiently via a physiologic pathway. When transferrinpolylysine conjugates were used to transduce airway epithelial cells grown in primary culture, however, gene transfer occurred inefficiently. Investigation into this relative inefficiency centered on endosomal entrapment of the conjugate-DNA complex. Pretreatment of the cells with chloroquine, which causes vacuolization and disruption of the endosome, or co-delivery of adenoviral particles, which serves to lyse the endosomal membrane, were both associated with greatly improved gene transfer efficiency. These studies established that the relative refractory state of the airway epithelial cells in primary culture was secondary to the retention of the internalized material within the endosome. We thus explored the efficiency of conjugates that possessed a mechanism to escape this endosomal entrapment; adenoviruspolylysine conjugates and transferrin-polylysine/adenovirus-polylysine conjugates were thus employed. Gene transfer efficiency improved significantly with the adenovirus-containing conjugates. These data support the concept that conjugates can be synthesized that mediate highly efficient gene transfer to airway epithelial cells in primary culture via the receptor-mediated endocytosis pathway.
\end{abstract}

Airway epithelial cells grown in primary culture have been transduced by a variety of techniques (1-5). These include the various DNA-mediated methodologies as well as recombinant viral vectors. These techniques have been extremely useful in elucidating aspects of airway cell biology. Additionally, definitive genetic therapeutic interventions for a variety of diseases affecting the respiratory tract, such as $\alpha_{1}$-antitrypsin and cystic fibrosis, may be feasible employing some of these gene delivery vectors (6-9). Despite the availability of these types of gene transfer vectors, technical and practical limitations involved in their employment have mandated that alternative vector systems be developed.

Initial attempts to express heterologous genes in airway

(Received in original form February 17, 1993 and in revised form June 9, 1993)

Address correspondence to: David T. Curiel, M.D., 1824 Sixth Ave. South, 620 Wallace Tumor Institute, University of Alabama-Birmingham, Birmingham, AL 35294.

Abbreviations: adenovirus-polylysine, AdpL; human airway epithelial cells, HAE cells; human transferrin-poly(L)lysine, hTfpL; human transferrinpolylysine/adenovirus-polylysine, hTfpL/AdpL.

Am. J. Respir. Cell Mol. Biol. Vol. 9. pp. 441-447, 1993 epithelial cells involved DNA-mediated methods. These have included calcium phosphate precipitated with DNA, liposome-directed DNA transfer, and DNA delivered by electroporation. Calcium phosphate precipitated with DNA was initially employed to transfect a variety of immortalized and primary cultures of cells (1). Use of this technique to achieve transient and long-term gene expression in bronchial epithelial cells, however, has been associated with significant toxicity. With strontium as an alternative cation, cytotoxicity was decreased but still significant (2). Cationic liposomes have also been used to transfer heterologous genes to airway epithelial cells $(3,4)$. This method involves the interaction of positively charged lipids with negatively charged DNA to form a complex that fuses with the cell membrane. This complex accomplishes delivery of the DNA to the cell, whereby expression of the delivered DNA can occur. Transient and stable expression of foreign genetic material has been achieved using this technique. Despite the relative ease of preparation, toxicity was also noted with this method, even after relatively short exposures (4). Exogenous genetic material has also been introduced into airway epithelial cells by electroporation (5). This technique is accomplished by mixing epithelial cells in suspensions with DNA and apply- 
ing a brief electrical pulse. Pores are briefly formed in the cell membrane allowing the DNA to enter the cell. In this procedure, cell viability was adversely affected, an effect that correlates with the strength of the electrical pulse.

As an alternative to these DNA-mediated methods, viral vectors have been used to transduce the airway epithelium. In this regard, efficient transduction has been noted with recombinant retroviral and adenoviral vectors (6-9). While these agents possess a higher efficiency of gene transfer, technical difficulties involved in their production have limited their widespread utility. In addition, these agents suffer from practical limitations related to the size of DNA that can be incorporated as well as potential interactions of heterologous DNA sequences with viral regulatory elements.

In this study, we have explored an alternative vector system to transduce airway epithelial cells in primary culture. This vector system exploits a normal cell entry pathway, receptor-mediated endocytosis, to accomplish delivery of exogenous genetic material to the cell (10-19). In this strategy, a ligand for a specific cell surface receptor is linked to a DNA-binding moiety-in this case, a polymer of positively charged amino acids, such as poly(L)lysine. When allowed to react with a nucleic acid, complexes form with the ligands on the exterior and the genetic material on the interior. This allows specific interaction with the cell surface receptor, followed by internalization. Confirmation that receptor-mediated endocytosis specifically directs delivery of the exogenous gene derives from the attenuation of gene transfer activity seen after the addition of an excess quantity of unconjugated ligand. This also serves to confirm that the specificity of the ligand for the receptor is unaltered after the linkage to the polylysine $(13,16)$. Potential advantages of this system include cell entry by a physiologic pathway, thereby reducing toxicity to the cell. Repetitive delivery is thus made possible. In addition, the design plasticity of this system allows the potential for specific cell targeting. Finally, given the synthetic nature of the components, large-scale preparation of the reagents can occur easily. We have previously shown that this method was effective in transducing immortalized cells of the airway epithelium $(16,19)$. In this study, we show this to be an effective method for the transduction of airway epithelial cells in primary culture.

\section{Materials and Methods}

\section{Preparation of Cells}

Two types of cellular targets derived from human airway epithelia were employed in this study. The HBEl cell line is an airway epithelial-derived cell line that has been immortalized by the human papilloma virus. HBEl cells were grown in Ham's F12/7X medium as previously described (20). In addition to immortalized airway epithelial cells, primary cultures of human airway epithelial (HAE) cells were employed. These were obtained from surgical specimens of nasal polyps by described techniques $(21,22)$. Briefly, Protease $\mathrm{XIV}$ and DNAse digestion at $4^{\circ} \mathrm{C}$ were used to dissociate the epithelial cells from the underlying submucosa. After enzymatic removal, the cells were filtered, pelleted, washed, and resuspended in Ham's F12/7X medium. They were then plated on $6-\mathrm{cm}$ plastic dishes at a density of $5 \times 10^{5}$ cells per plate. After approximately 2 to 3 days in culture, the cells were 50 to $75 \%$ confluent.

\section{Preparation of Molecular Conjugate Vectors}

Various species of molecular conjugate vectors were evaluated for their ability to transduce airway epithelial cells. $\mathrm{Hu}$ man transferrin-poly(L)lysine (hTfpL; Serva Biochemicals) is a binary conjugate consisting of transferrin covalently linked to poly(L)lysine. To form complexes with DNA, 12 $\mu \mathrm{g} \mathrm{hTfpL}$ in $150 \mu \mathrm{l} \mathrm{HBS}(150 \mathrm{mM} \mathrm{NaCl}+20 \mathrm{mM}$ Hepes, $\mathrm{pH}$ 7.3) was combined with $6 \mu \mathrm{g}$ plasmid DNA in $350 \mu \mathrm{l}$ HBS. This mixture was allowed to react for $30 \mathrm{~min}$ at room temperature before application to cells.

Adenovirus-polylysine (AdpL) is a binary conjugate, which is composed of an adenovirus linked to poly $(\mathrm{L})$ lysine. In this configuration, the adenovirus moiety serves both as a ligand and as an agent to accomplish the lysis of the endocytotic vesicle, enhancing the overall gene transfer efficiency of this conjugate. The adenoviruses used in this construction were either P259-Ad5 or P202-Ad5. P202-Ad5 is an adenovirus type 5 that has been altered such that a portion of the hexon capsid protein contains a heterologous epitope to allow an immunologic linkage to poly $(\mathrm{L})$ lysine $(23,24)$. P259-Ad5 is derived from P202-Ad5 but has a deletion in the E1A/E1B regions, making it replication-incompetent (25). Adenovirus-component complexes were formed by the sequential addition of antibody-polylysine (MP301pL) in 250 $\mu \mathrm{l} \mathrm{HBS}$ to $2.5 \times 10^{10}$ viral particles. After $30 \mathrm{~min}$ of incubation, $6 \mu \mathrm{g}$ of plasmid DNA in $125 \mu \mathrm{l} \mathrm{HBS}$ was added. This mixture was also allowed to react for $30 \mathrm{~min}$. Finally, $6 \mu \mathrm{g}$ poly(L)lysine (pL295) was added to complete the formation of the gene delivery vector.

Human transferrin-polylysine/adenovirus-polylysine (hTfpL/AdpL) is a ternary conjugate that possesses both transferrin and the adenovirus. In the configuration, transferrin serves as a ligand with the adenovirus serving as an alternate ligand and as an endosomal lysis agent. This ternary complex is formed as above for AdpL. However, in the last step, instead of the addition of pL295, human transferrinpolylysine $(6 \mu \mathrm{g})$ in $125 \mu \mathrm{l}$ HBS was added.

The various conjugate species were used in transduction experiments. To transduce cells, $1 \mathrm{ml}$ of Ham's $6 \mathrm{X}$ medium (Ham's F12/7X lacking transferrin) was added to each plate followed by $500 \mu \mathrm{l}$ of the conjugate-DNA complex. After this incubation, the plates were then returned to the incubator $\left(37^{\circ} \mathrm{C}, 5 \% \mathrm{CO}_{2}\right)$ for $1 \mathrm{~h}$. The plate was then supplemented with an additional $1.5 \mathrm{ml}$ of Ham's F12/7X medium, and the cells were incubated for a given period of time prior to the analysis of gene expression.

\section{Reagents}

Agents that affected the endosome/lysosome cellular pathway were employed in some of the gene transfer experiments. Chloroquine $\mathrm{HCl}$ (Sigma Chemical Co., St. Louis, MO) was used to cause osmotic disruption of the endosome. This was utilized as a solution at a final concentration of $100 \mu \mathrm{M}$.

Adenoviruses were employed for their utility as agents that disrupt the endosome membrane of target cells. For these studies, the adenovirus $\mathrm{dl} 312$ was used (26). This virus is replication-defective based on the deletion of the E1A region and a portion of the E1B region. Propagation of these virions was in the cell line 293, which complements the deleted viral genes. After production, viral particles were isolated by two rounds of cesium chloride centrifugation. 
They were then diluted with glycerol and frozen at $-70^{\circ} \mathrm{C}$.

\section{Analysis of Gene Transfer}

To analyze net gene transfer, two plasmid DNAs encoding the luciferase gene were used. The plasmid pRSVL has the Rous sarcoma virus long terminal enhancer/promoter driving the expression of a firefly luciferase gene (27). The plasmid PCMVL has the cytomegalovirus immediate early promoter/enhancer controlling the transcription of the firefly luciferase gene (28). Cells transduced by the various conjugate species were harvested, and cell lysates assayed for expression of the luciferase gene product. Assay of the luciferase activity of transduced cells was as described (16). Experiments were performed 2 to 4 times each.

To determine the percentage of cells transduced, the plasmid $\mathrm{pCMV} \beta$, encoding for the $\beta$-galactosidase gene, was used (29). This plasmid contains the CMV immediate early promoter directing the synthesis of the bacterial enzyme $\beta$-galactosidase. The activity of this enzyme in transduced cells was then demonstrated by fixing in paraformaldehyde and addition of 5-bromo-4-chloro-3-indolyl- $\beta$-D-galactoside (X-gal).

\section{Results \\ Gene Transfer to Human Airway Epithelial \\ Cells via the Transferrin Pathway}

Experiments were carried out to determine whether airway epithelial cells in primary culture could be transduced via the transferrin internalization pathway. In these studies, transferrin-polylysine conjugates complexed with pRSVL were applied to the immortalized airway epithelial cell line, HBEl, and airway epithelial cells in primary culture. Analysis of net

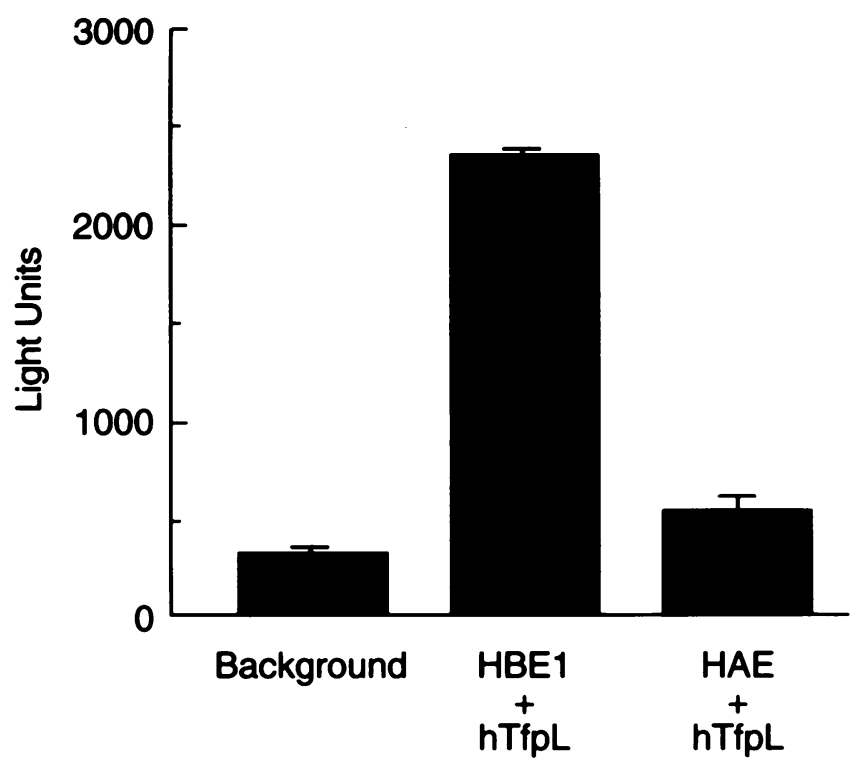

Figure 1. Receptor-mediated gene transfer to HBE1 cells and human airway epithelial (HAE) cells in primary culture. Human transferrin-polylysine $(12 \mu \mathrm{g})$ was combined with the reporter plasmid pRSVL $(6 \mu \mathrm{g})$ and delivered to cells. Cells were harvested at $24 \mathrm{~h}$, and lysates were evaluated for luciferase gene expression after standardization for protein content. gene expression demonstrated transduction of the HBEl cells while the cells in primary culture exhibited luciferase levels similar to that observed in nontransduced control cells. Specifically, as depicted in Figure 1, heterologous gene expression in HBEl cells was approximately 6 times background, whereas in the analysis of the primary cells, levels did not differ significantly from the background value. Thus, these two types of cells of airway epithelial derivation differed markedly in their susceptibility to gene transfer via the transferrin pathway.

To explore this difference in susceptibility to the transferrin-polylysine conjugates, two hypotheses were considered. Different populations of transferrin receptors, and thus differences in the ability of the target cells to internalize the conjugate, could explain this difference. Alternatively, the fates of the endocytosed material could be different in the cell populations. Since it has been established that efficiency of gene transfer via the receptor-mediated endocytosis pathway can be limited by entrapment of the delivered DNA within the endosome $(15,19)$, this possibility was initially considered as an explanation in this instance.

\section{Effect of Modulation of Endosome/Lysosome Pathway on the Efficiency of Gene Transfer by Transferrin-Polylysine Conjugates}

To determine whether lysosomal degradation contributed to the relatively limited gene transfer efficacy of the conjugatedelivered DNA noted in cells grown in primary culture, we employed chloroquine, an agent that causes vacuolization of the endosome and subsequent release of the endocytosed material (30). After being treated with chloroquine for $4 \mathrm{~h}$, these cells were washed with media and transduced with transferrin-polylysine-pCMVL-DNA complex. Analysis of the cells at $24 \mathrm{~h}$ showed augmentation in gene transfer efficiency as shown (Figure 2). This finding was consistent with the concept that gene transfer was limited by the delivery of the conjugate-DNA complex to the lysosomal pathway. As an additional strategy to confirm the contribution of endosomal entrapment to the limited conjugate efficiency, we employed the adenovirus $\mathrm{dl} 312$ as an agent to accomplish disruption of the endosome. In this regard, it is known that adenoviruses facilitate the exit of delivered DNA from the endosome and thus enhance conjugate-mediated gene delivery (19). In this study, cells were co-treated with $2.5 \times$ $10^{10} \mathrm{dl} 312$ adenoviral particles and the transferrin-polylysine-plasmid DNA complex. It can be seen in Figure 2 that gene expression employing this agent was significantly augmented compared with transferrin-polylysine-plasmid DNA alone. These findings were consistent with the concept that the limitation of conjugate gene transfer efficiency in human airway epithelial cells in primary culture is principally due to the entrapment of the delivered DNA within the endocytotic compartment and subsequent degradation. Furthermore, overall gene transfer efficiency could be augmented by employing maneuvers to overcome cell vesicle entrapment.

\section{Gene Transfer to Human Cells in Primary Cultures with Conjugates that Possess Endosome Lysis Activity}

Since it was demonstrated that endosomal entrapment of the heterologous gene limited conjugate efficiency in human air- 


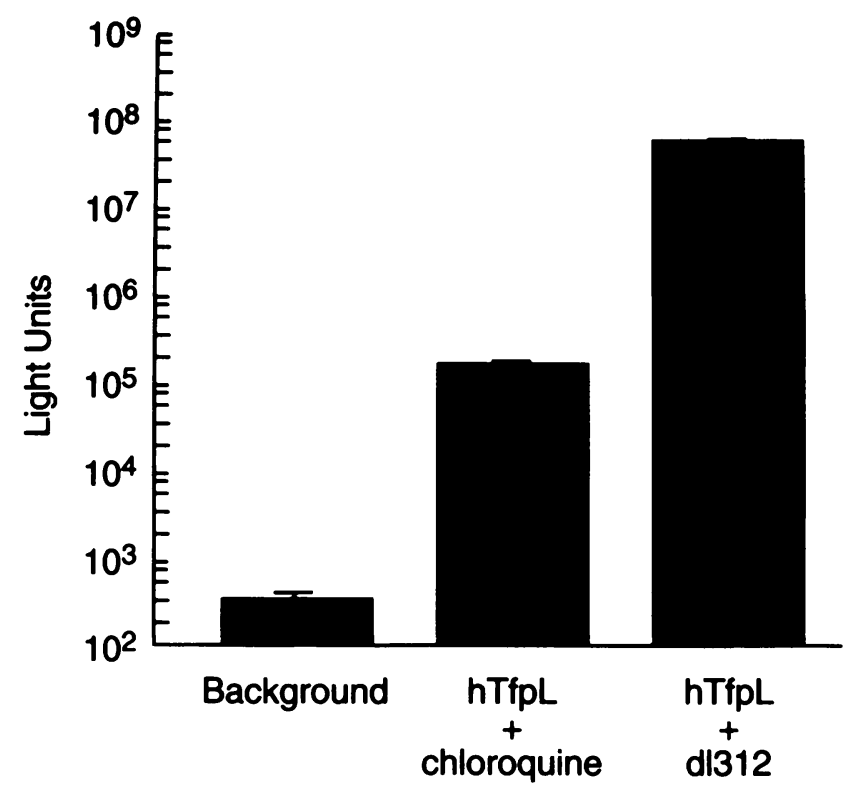

Figure 2. Effect of agents that modulate endosomal/lysosomal pathway on human transferrin-polylysine-mediated gene transfer to human airway epithelial cells. Human transferrin-polylysine (12 $\mu \mathrm{g})$ was complexed with pCMVL $(6 \mu \mathrm{g})$ plasmid DNA. Cells were then treated either with chloroquine $\mathrm{HCl}$ at a final concentration of $100 \mu \mathrm{M}$ or $2.5 \times 10^{10} \mathrm{dl} 312$ adenovirus particles per plate. Samples were harvested at $24 \mathrm{~h}$ and aliquots were analyzed for luciferase activity as previously described.

way epithelial cells in primary culture, we explored the utility of conjugates that possessed endosomal lysis activity as part of their functional design. Initially, we compared net gene expression using the various conjugate species. Transferrin-polylysine conjugates, adenovirus-polylysine conjugates, and transferrin-polylysine/adenovirus-polylysine conjugates were delivered to cells of human airway epithelial origin grown in primary culture. Consistent with the concept that delivered DNA was significantly retained within the endosome, data in Figure 3 demonstrate that the conjugates containing the adenovirus showed increased gene expression compared with the transferrin-polylysine conjugates. This reflects the fact that the adenovirus-containing conjugates possessed a mechanism to escape entrapment and thus are more efficacious in accomplishing gene transfer. Interestingly, the transferrin-polylysine/adenovirus-polylysine conjugate, which possesses two mechanisms for cellular entry, demonstrated a further advantage over the construct that enters cells by the adenoviral receptor alone. In this configuration, the presence of a second ligand allows enhanced entry and thus augmented gene expression. Additionally, the enhanced gene transfer efficiency seen with the transferrinpolylysine/adenovirus-polylysine conjugates compared with that seen with free virus likely results from the nuclear localization capacity of the adenoviral capsid. Once the adenovirus has escaped from the endosome, it localizes to the nucleus. Indeed, electron microscopy has clearly demonstrated attachment of viral particles to the nuclear membrane during the infection process $(24,31)$. Similar experiments were repeated using airway epithelial cells in primary culture

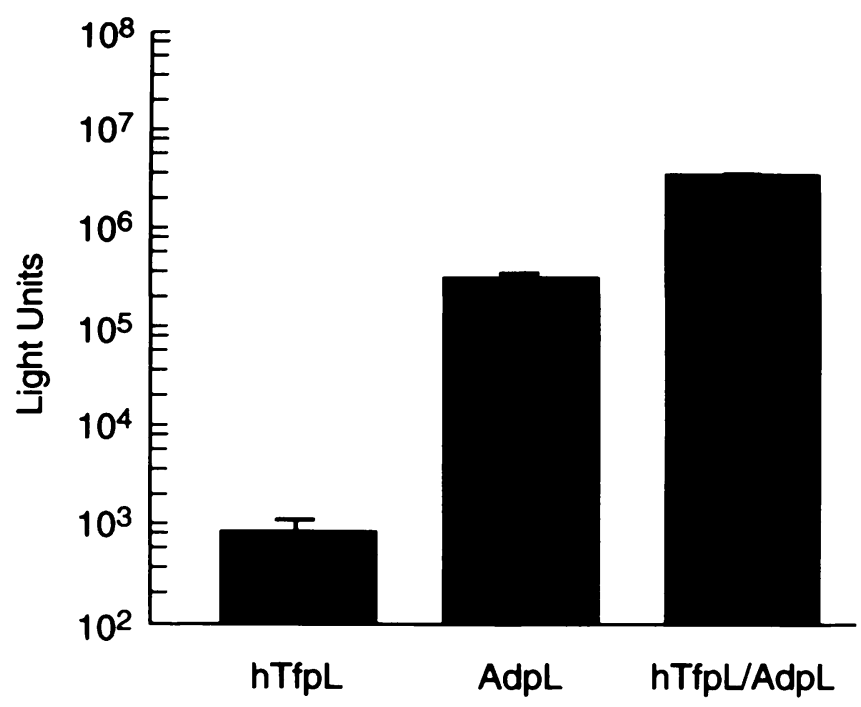

Figure 3. Gene transfer to airway epithelial cells using various species of molecular conjugates. Transferrin-polylysine (hTfpL), adenovirus-polylysine (AdpL), and transferrin-polylysine/adenovirus-polylysine (hTfpL/AdpL) conjugates were prepared as described above and delivered to cells derived from the airway epithelium. At $24 \mathrm{~h}$, cell lysates were analyzed for luciferase enzyme activity.

from mouse, monkey, and ferret lung. In all of these experiments, significantly augmented gene transfer was again noted with the adenovirus-containing conjugates compared with conjugates lacking endosome lysis activity (data not shown).

To determine whether the level of net gene transfer correlated with the transduction frequency of the total available population, the histologic reporter $\beta$-galactosidase was used in conjunction with the conjugates. Conjugates were formed with $\mathrm{pCMV} \beta$ and incubated with the airway epithelial cells. At $24 \mathrm{~h}$, the cells were fixed and $\beta$-galactosidase activity was detected as described. Microscopic examination shown in Figure 4 demonstrated that the transferrin-polylysine conjugates transduced fewer than $1 \%$ of cells. Approximately $8 \%$ of the cells were transduced by the adenovirus-polylysine conjugates and greater than $25 \%$ of the cells were transfected with the transferrin-polylysine/adenovirus-polylysine conjugates. This demonstrates that the relative level of gene transfer found in the experiments with the luciferase gene correlated with the percentage of cells transduced in these experiments. These data also illustrate that highly efficient gene transduction could be achieved with this gene transfer method.

\section{Time Course of Gene Expression in Primary Cultures of Human Airway Epithelial Cells}

Because the DNA delivered by this method possesses no specific integration mechanism, it would be anticipated to have transient expression only. To explore the time course of this gene expression, we evaluated net gene expression over a 7-day period. Adenovirus-polylysine conjugates complexed with PRSVL plasmid DNA were delivered to cultures of human airway epithelial cells. Cells were lysed at days 1, 3, 5, and 7 ; lysates were frozen at $-70^{\circ} \mathrm{C}$ until the time of assay. 
Figure 4. Determination of transduction frequency to airway epithelial cells using various species of molecular conjugates. Conjugates were formed as described in Figure 3, with the exception of the use of the plasmid $\mathrm{pCMV} \beta$. Conjugates were delivered to cells, and analysis of gene expression occurred at $24 \mathrm{~h}$. Figure $4 \mathrm{a}$ represents cells transduced with hTfpL, whereas Figures $4 b$ and $4 c$ depict a representative field of cells transduced with AdpL and hTfpL/AdpL, respectively.
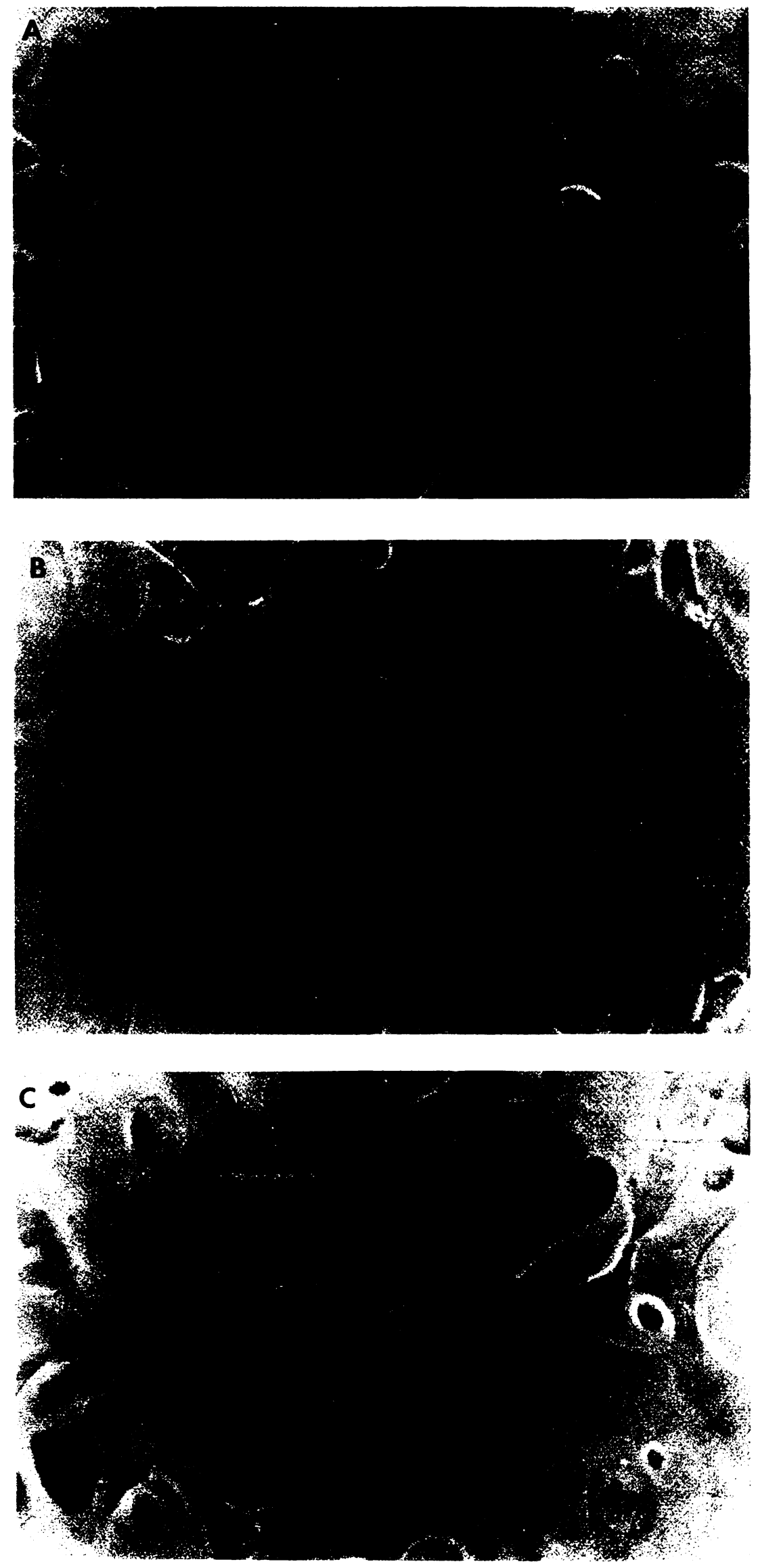


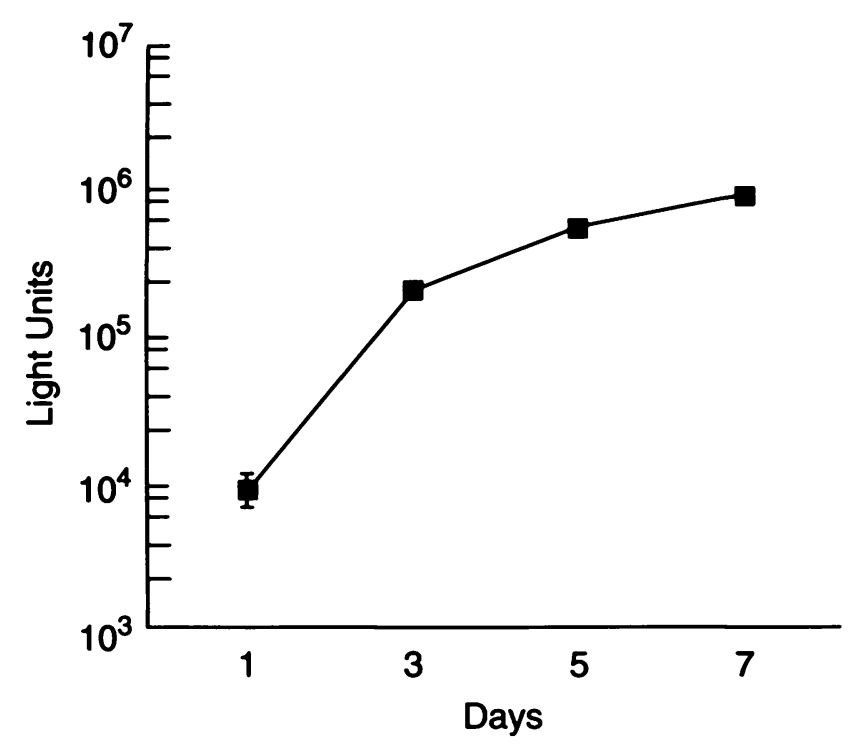

Figure 5. Time course of gene expression of human airway epithelial cells transduced with adenovirus-polylysine conjugates. Adenovirus-polylysine conjugates complexed with the reporter pRSVL were delivered to primary airway cells as before. Lysates were analyzed at days $1,3,5$, and 7 .

Evaluation of the data in Figure 5 shows that gene expression continued and, indeed, increased over this interval. This indicates that the DNA delivered by this route remained within the cell during this period and was not eliminated. Examination of latter time points in rodent primary airway epithelial cells showed diminution of expression of the heterologous gene after 1 wk (data not shown).

\section{Discussion}

Gene transfer by the receptor-mediated endocytosis pathway offers an efficient and physiologic scheme for the delivery of exogenous DNA. Because the heterologous DNA enters the cell by a normal cell internalization pathway, the cell is not perturbed to any appreciable degree during the transduction process. The safety of the delivery technique thus permits cells to be transduced on a repetitive basis. It is significant to note that the potential exists to achieve cell-specific targeting, i.e., conjugates may be synthesized for a target cell of interest if information is known about particular receptors on the cell surface. In this regard, Wu and co-workers have shown that conjugates synthesized with asialoglycoprotein as targeting ligand can deliver foreign genetic material with specificity to the liver $(11,12)$. This capacity for cell-specific targeting may also allow particular cells within an organ's heterogeneous cell population to be specifically targeted if particular receptors are known that clearly delineate these various cell types. In addition, this gene transfer method offers several other potential advantages. In this regard, construction of conjugates is technically simple. Finally, the conjugates are able to deliver large DNA molecules to the target cell and, since the DNA interacts with the polylysine in a sequence-independent manner, DNA of any design may be delivered.
As previously shown, HBEl cells, an immortalized airway epithelial cell line, were readily transduced by the transferrin-polylysine conjugates (16). However, airway epithelial cells grown in primary culture were not susceptible to gene transfer by this route. The difference in transduction efficiency could have been due to either differences in the receptor density on the respective cell surfaces or due to changes in the fate of the endocytosed material in these two cell types. The data derived in this study suggest that the degradative pathway of the lysosome functions particularly well in the cells taken directly from the airway epithelium and that agents that inhibit or subvert this pathway, namely chloroquine and the adenovirus, increase gene transfer efficiency substantially. This limitation could be overcome when conjugates were formed that had the capacity to escape lysosomal degradation within the primary cell. Chloroquine is thought to increase gene transfer activity because of its ability to cause vacuolization of the endosome. After endocytosis and endosome formation, release of the ligand from the cell vesicle occurs as a result of disruption of this subcellular compartment. In this regard, proton pumps serve to lower the $\mathrm{pH}$ by translocation of the $\mathrm{H}^{+}$into the endosome. When chloroquine is present within the endosome during the acidification process, it acts as an osmotic agent, causing the endosome to swell and subsequently burst. This then allows endosomal escape of the conjugate-DNA complex, with the result being increased expression of the internalized DNA. The adenovirus is also known to increase gene transfer efficiency by allowing escape of the endocytosed material from the endosome. Uptake of the adenovirus by the cell occurs by the receptor-mediated endocytosis pathway. Receptors cluster on the cell surface and clathrin-coated pits form. Endosomes are then formed, containing the ligand attached to the cell surface receptor. As mentioned above, acidification of the endosome occurs by a membrane-found proton pump. This causes a conformational change in the capsid protein of the virus, allowing interaction of the hydrophobic domains of the viral capsid with the endosome membrane, causing endosome disruption (32). This vesicle disruption step serves to allow delivery of the endosomal contents to the cytoplasm (31). Overall, we have shown increased gene transfer activity both qualitatively, with the luciferase data, and quantitatively, with the $\beta$-galactosidase histologic data.

In summary, data are presented for gene delivery by the receptor-mediated endocytosis route to airway epithelial cells grown in primary culture. Highly efficient transduction of these cells is noted when the adenovirus is used to function as an agent that lyses the endosome in the conjugate vector. This allows the delivered DNA to escape from the endosome, thereby allowing completion of gene transfer in these cells, which exhibit a physiologic level of endosomal degradation.

Acknowledgments: We wish to thank Lisa Brown for expert editorial assistance and James Yankaskas for provision of HBE1 cells and primary airway epithelial cells.

\section{References}

1. Gruenert, D. C., C. B. Basbaum, M. J. Welsh, M. Li, W. E. Finkbeiner, and J. A. Nadel. 1988. Characterization of human tracheal epithelial cells transformed by an origin-defective simian virus 40. Proc. Natl. Acad. Sci. 
USA 85:5951-5955.

2. Brash, D. E., R. R. Reddel, M. Quanrud, K. Yang, M. P. Farrell, and C. C. Harris. 1987. Strontium phosphate transfection of human cells in primary culture: stable expression of the simian virus 40 large- $\mathrm{T}$-antigen gene in primary human bronchial epithelial cells. Mol. Cell Biol. 7:2031-2034.

3. Hazinski, T. A., P. A. Ladd, and C. A. DeMatteo. 1991. Localization and induced expression of fusion genes in the rat lung. Am. J. Respir. Cell Mol. Biol. 4:206-209.

4. Lu, L., P. L. Zeitlin, W. B. Guggino, and R. W. Craig. 1989. Gene transfer by lipofection in rabbit and human secretory epithelial cells. Pflugers Arch. 415:198-203.

5. Iannuzzi, M. C., J. L. Weber, J. Yankaskas, R. Boucher, and F. S. Collins. 1988. The introduction of biologically active foreign genes into human respiratory epithelial cells using electroporation. Am. Rev. Respir. Dis. 138:965-968

6. Rosenfeld, M. A., W. Siegfried, K. Yoshimura, K. Yoneyama, M. Fukayama, L. E. Stier, P. K. Paakko, P. Gilardi, L. D. StratfordPerricaudet, M. Perricaudet, S. Jallat, A. Pavirani, J.-P. Lecocq, and R. G. Crystal. 1991. Adenovirus-mediated transfer of a recombinant $\alpha 1$ antitrypsin gene to the lung epithelium in vivo. Science 252:431-434.

7. Rich, D. P., M. P. Anderson, R. J. Gregory, S. H. Cheng, S. Paul, D. M. Jefferson, J. D. McCann, K. W. Klinger, A. E. Smith, and M. J. Welsh. 1990. Expression of cystic fibrosis transmembrane conductance regulator corrects defective chloride channel regulation in cystic fibrosis airway epithelial cells. Nature 347:358-363.

8. Johnson, L. G., J. C. Olsen, B. Sarkadi, K. L. Moore, R. Swanstrom, and R. C. Boucher. 1992. Efficiency of gene transfer for restoration of normal airway epithelial function in cystic fibrosis. Nature Genet. 2:21-25.

9. Rosenfeld, M. A., K. Yoshimura, B. C. Trapnell, K. Yoneyama, E. R. Rosenthal, W. Dalemans, M. Fukayama, J. Bargon, L. E. Stier, L. Stratford-Perricaudet, M. Perricaudet, W. B. Guggino, A. Pavirani, J.-P. Lecocq, and R. G. Crystal. 1992. In vivo transfer of the human cystic fibrosis transmembrane conductance regulator gene to the airway epithelium. Cell 68:143-155.

10. Zenke, M. P. Steinlein, E. Wagner, M. Cotten, H. Beug, and M. L. Birnstiel. 1990. Receptor-mediated endocytosis of transferrin-polycation conjugates: an efficient way to introduce DNA into hematopoietic cells. Proc. Natl. Acad. Sci. USA 87:3655-3659.

11. Wu, G. Y., and C. H. Wu. 1987. Receptor-mediated in vitro gene transformation by a soluble DNA carrier system. J. Biol. Chem. 262:4429-4432.

12. Wu, C. H., J. M. Wilson, and G. Y. Wu. 1989. Targeting genes: delivery and persistent expression of a foreign gene driven by mammalian regulatory elements in vivo. J. Biol. Chem. 264:16985-16987.

13. Wagner, E., M. Zenke, M. Cotten, H. Beug, and M. L. Birnstiel. 1990. Transferrin-polycation conjugates as carriers for DNA uptake into cells. Proc. Natl. Acad. Sci. USA 87:3410-3414.

14. Wagner, E., M. Cotten, K. Mechtler, H. Kirlappos, and M. L. Birnstiel. 1991. DNA-binding transferrin conjugates as functional gene-delivery agents: synthesis by linkage of polylysine or ethidium homodimer to the transferrin carbohydrate moiety. Bioconjug. Chem. 2:226-231.

15. Cotten, M., F. Langle-Rouault, H. Kirlappos, E. Wagner, K. Mechtler, M. Zenke, H. Beug, and M. L. Birnstiel. 1990. Transferrin-polycationmediated introduction of DNA into human leukemic cells: stimulation by agents that affect the survival of transfected DNA or modulate transferrin receptor levels. Proc. Natl. Acad. Sci. USA 87:4033-4037.

16. Curiel, D. T., S. Agarwal, M. U. Rømer, E. Wagner, M. Cotten, M. L.
Birnstiel, and R. C. Boucher. 1992. Gene transfer to respiratory epithelial cells via the receptor-mediated endocytosis pathway. Am. J. Respir. Cell Mol. Biol. 6:247-252.

17. Huckett, B., M. Ariatti, and A. O. Hawtrey. 1990. Evidence for targeted gene transfer by receptor-mediated endocytosis. Biochem. Pharmacol. 40:253-263.

18. Rosenkranz, A. A., S. V. Yachmenev, D. A. Jans, N. V. Serebryakova, V. I. Murav'ev, R. Peters, and A. S. Sobolev. 1992. Receptor-mediated endocytosis and nuclear transport of a transfecting DNA construct. Exp. Cell Res. 199:323-329.

19. Curiel, D. T., S. Agarwal, E. Wagner, and M. Cotten. 1991. Adenovirus enhancement of transferrin-polylysine-mediated gene delivery. Proc. Natl. Acad. Sci. USA 88:8850-8854.

20. Yankaskas, J. R., J. E. Haizlip, M. Conrad, D. Koval, E. Lazarowski, A. M. Paradiso, C. A. Rinehart, Jr., B. Sarkadi, R. Schlegel, and R. C. Boucher. 1993. Papilloma virus immortalized tracheal epithelial cells retain a well-differentiated phenotype. Am. J. Physiol. (In press)

21. Wu, R., J. Yankaskas, E. Cheng, M. R. Knowles, and R. Boucher. 1985 Growth and differentiation of human nasal epithelial cells in culture. Am. Rev. Respir. Dis. 132:311-320.

22. Yankaskas, J. R., C. U. Cotton, M. R. Knowles, J. T. Gatzy, and R. C Boucher. 1985. Culture of human nasal epithelial cells on collagen matrix supports. Am. Rev. Respir. Dis. 132:1281-1287.

23. Curiel, D. T., E. Wagner, M. Cotten, M. L. Birnstiel, S. Agarwal, C.-M Li, S. Loechel, and P.-C. Hu. 1992. High-efficiency gene transfer mediated by adenovirus coupled to DNA-polylysine complexes. Hum. Gene Ther. 3:147-154.

24. Curiel, D. T. 1993. Adenovirus facilitation of molecular conjugate-mediated gene transfer. In Progress in Medical Virology. J. L. Melnick, editor. Karger, Basel. 1-18.

25. Curiel, D. T. 1993. Receptor-mediated gene delivery employing adenovirus-polylysine-DNA complexes. Gene Ther. (In press)

26. Jones, N., and T. Shenk. 1979. An adenovirus type 5 early gene function regulates expression of other early viral genes. Proc. Natl. Acad. Sci. USA 76:3665-3669.

27. deWet, J. R., K. V. Wood, M. DeLuca, D. R. Helinski, and S. Subramani. 1987. Firefly luciferase gene: structure and expression in mammalian cells. Mol. Cell. Biol. 7:725-737.

28. Plank, C., K. Zatloukal, M. Cotten, K. Mechtler, and E. Wagner. 1992. Gene transfer into hepatocytes using asialoglycoprotein receptor mediated endocytosis of DNA complexed with an artificial tetra-antennary galactose ligand. Bioconjug. Chem. 3:533-539.

29. MacGregor, G. R., and C. T. Caskey. 1989. Construction of plasmids that express E. coli $\beta$-galactosidase in mammalian cells. Nucleic Acids Res. 17:2365

30. Zatloukal, K., E. Wagner, M. Cotten, S. Phillips, C. Plant, P. Steinlein, D. T. Curiel, and M. L. Birnstiel. 1992. Transferrinfection: a highly efficient way to express gene constructs in eukaryotic cells. Ann. NY Acad. Sci. 660:136-153.

31. FitzGerald, D. J. P., R. Padmanabhan, I. Pastan, and M. C. Willingham. 1983. Adenovirus-induced release of epidermal growth factor and Pseudomonas toxin into the cytosol of KB cells during receptor-mediated endocytosis. Cell 32:607-617.

32. Pastan, I., P. Seth, D. FitzGerald, and M. Willingham. 1986. Adenovirus entry into cells: some new observations on an old problem. In Virus Attachment and Entry into Cells. R. L. Crowell and K. Lonberg-Holm, editors. American Society for Microbiology, Washington, D.C. 141-146. 